\title{
Management of hereditary dyslipidaemia; the paradigm of autosomal dominant hypercholesterolaemia
}

\author{
Sigrid W Fouchier ${ }^{1}$, Jessica Rodenburg ${ }^{1}$, Joep C Defesche ${ }^{*, 1}$ and John JP Kastelein ${ }^{1}$ \\ ${ }^{1}$ Department of Vascular Medicine, Academic Medical Centre at the University of Amsterdam, Amsterdam, \\ The Netherlands
}

Inherited, or autosomal dominant, hypercholesterolaemia, with an average global prevalence of one in 500 individuals, is one of the most frequent inherited metabolic disorders. The disorder is associated with a high risk for premature cardiovascular disease (CVD) and death as a consequence of accelerated atherosclerosis. Although the molecular genetic basis is largely elucidated and effective medical treatment, in the form of inhibitors of intracellular cholesterol synthesis, is available, the disorder is severely underdiagnosed and undertreated. On the other hand, with the well-understood aetiology, the accurate diagnosis, the availability of sensitive predictive makers and efficacious therapy, this disorder can serve as a model for disease management: from early presymptomatic diagnosis, accurate prognosis, optimal treatment and large-scale screening to population-based prevention of CVD. European Journal of Human Genetics (2005) 13, 1247-1253. doi:10.1038/sj.ejhg.5201496; published online 28 September 2005

Keywords: $\mathrm{ADH}$; FH; FDB; IMT; population; screening

\section{Clinical aspects}

Autosomal dominant hypercholesterolaemia (ADH) is clinically characterized by elevated total and low-density lipoprotein (LDL) cholesterol levels in plasma. ${ }^{1}$ The elevated LDL-cholesterol (LDL-C) levels lead to excessive deposition of cholesterol in arterial walls, which eventually results in accelerated atherosclerosis and premature cardiovascular disease (CVD). Additionally, and also as a result of these elevated LDL-C levels, tendon xanthomas, xanthelamata and an arcus cornealis may be found. The onset and severity of CVD varies considerably in each ADH patient, which primarily depends on the severity of the elevated cholesterol levels and secondly on other risk factors. These risk factors include: age (men over 45,

*Correspondence: Dr JC Defesche, Department of Vascular Medicine, Academic Medical Centre, University of Amsterdam, G1-112B, PO Box 22660, 1100 DD Amsterdam, The Netherlands. Tel: + 3120566 4855; Fax: + 3120566 9232; E-mail: j.defesche@amc.uva.nl Received 2 March 2005; revised 2 August 2005; accepted 16 August 2005; published online 28 September 2005 women over 55 years), family history of premature CVD, cigarette smoking, hypertension (over 140/90 $\mathrm{mmHg}$ ), low HDL cholesterol (below $35 \mathrm{mg} / \mathrm{dl}$ or $0.9 \mathrm{mmol} / \mathrm{l}$ ) and diabetes mellitus. ${ }^{2}$ ADH patients can roughly be divided into four risk categories (Table 1$){ }^{3}$

Untreated, $75 \%$ of male ADH patients suffer from CVD before the age of 60 years. ${ }^{4}$ Characteristically, the mean age of onset of CVD is between 40 and 45 years in men and between 50 and 55 years in women with $\mathrm{ADH}$.

Heterozygous $\mathrm{ADH}$ has a prevalence of approximately one in 500 individuals, making it one of the most common inherited disorders. The diagnosis of $\mathrm{ADH}$ is usually made on the basis of clinical signs, but, since the physical stigmata of $\mathrm{ADH}$ develop later in life, establishing the diagnosis in younger patients is often difficult. ${ }^{1}$ Genetic analysis, that is, the demonstration of a causative mutation, provides the only unequivocal diagnosis.

\section{Genetic aspects}

The most prevalent underlying molecular defect of $\mathrm{ADH}$ consists of mutations in the gene coding for the 
Table 1 Risk categories for ADH patients (LDL-C in $\mathrm{mmol} / \mathrm{l}(\mathrm{mg} / \mathrm{dl})$ )

\begin{tabular}{ll}
\hline Risk category & LDL cholesterol and additional risk factors \\
\hline High risk & Existing CVD or CVD risk equivalents, 10-year risk $>20 \%$ and LDL-C $\geq 2.6(100)$ \\
Moderately high risk & Two or more risk factors, 10-year risk 10-20\% and LDL-C $\geq 3.4(130)$ \\
Moderate risk & Two or more risk factors, 10-year risk $<10 \%$ and LDL-C $\geq 4.1(160)$ \\
Low risk & $0-1$ risk factor and LDL-C $\geq 4.6(190)$ \\
\hline
\end{tabular}

The 10-year risk is the risk to develop cardiovascular disease within the next 10 years.

CVD risk equivalents are diabetes or other forms of atherosclerotic disease, that is, peripheral arterial disease.

Table 2 Adult Treatment Panel III (ATPIII) LDL-C goals and cutpoints for the initiation of therapeutic lifestyle changes (TLC) and drug therapy in the different risk categories

\begin{tabular}{lccr}
\hline Risk category & LDL-C target level & Initiate TLC when & Consider drug therapy when \\
\hline High risk & $<2.6 \mathrm{mmol} / \mathrm{l}(100 \mathrm{mg} / \mathrm{dl})$ & $\geq 2.6 \mathrm{mmol} / \mathrm{l}(100 \mathrm{mg} / \mathrm{dl})$ & $\geq 2.6 \mathrm{mmol} / /(100 \mathrm{mg} / \mathrm{dl})^{\mathrm{a}}$ \\
Moderately high risk & $<3.4 \mathrm{mmol} / \mathrm{l}(130 \mathrm{mg} / \mathrm{dl})$ & $\geq 3.4 \mathrm{mmol} / \mathrm{l}(130 \mathrm{mg} / \mathrm{dl})$ & $\geq 3.4 \mathrm{mmol} / \mathrm{l}(130 \mathrm{mg} / \mathrm{dl})^{\mathrm{a}}$ \\
Moderate risk & $<3.4 \mathrm{mmol} / \mathrm{l}(130 \mathrm{mg} / \mathrm{dl})$ & $\geq 3.4 \mathrm{mmol} / \mathrm{l}(130 \mathrm{mg} / \mathrm{dl})$ & $\geq 4.1 \mathrm{mmol} / \mathrm{l}(160 \mathrm{mg} / \mathrm{dl})$ \\
Low risk & $<4.1 \mathrm{mmol} / \mathrm{l}(160 \mathrm{mg} / \mathrm{dl})$ & $\geq 4.1 \mathrm{mmol} / \mathrm{l}(160 \mathrm{mg} / \mathrm{dl})$ & $\geq 4.9 \mathrm{mmol} / \mathrm{l}(190 \mathrm{mg} / \mathrm{dl})$ \\
\hline
\end{tabular}

LDL-C: LDL cholesterol.

an addition to dietary therapy.

LDL-receptor protein. LDL particles bind to the LDL receptor, are internalized and metabolized in the liver. Mutations in the LDL-receptor gene (LDLR) impair the internalization of the LDL particle, resulting in elevated LDL-C levels in the circulation. ADH patients with an identified $L D L R$ mutation are diagnosed with familial hypercholesterolaemia $(\mathrm{FH}) .{ }^{1}$ To date, more than 840 different mutations are known in the $L D L R$, which underlay FH. New mutations are identified on a regular basis. ${ }^{5,6}$ Crucial for the actual binding between the LDL receptor and the LDL particle is the presence of apolipoprotein B (APOB), the structural protein of the LDL particle. Mutations in the LDL-receptor-binding domain of the APOB protein are also known to cause high LDL-C levels. Five different mutations located in this region of the $A P O B$ gene are reported to cause a high cholesterol phenotype. These patients are diagnosed as familial defective APOB (FDB), which is clinically indistinguishable from FH. ${ }^{1,7}$ Not all $\mathrm{ADH}$ cases can be explained on a molecular level by a mutation in the $L D L R$ or $A P O B$ gene. ${ }^{8}$ In an attempt to elucidate the genetic background of the molecularly uncharacterized $\mathrm{ADH}$ population, intensive research has been carried out in the past years, and has resulted in the identification of a third putative $\mathrm{ADH}$ locus located on chromosome 1 , encoding the proprotein convertase subtilisin/kexin 9 (PCSK9). ${ }^{9}$ To date, only three mutations are reported in this gene, cosegregating with a high cholesterol phenotype. $^{9-11}$ Screening for mutations in this gene in 300 $\mathrm{ADH}$ patients of Dutch descent, in which $L D L R$ and $A P O B$ were excluded, resulted in the identification of four genetic variants not present in 400 control individuals. Subsequent examination of the families in which these variants were present demonstrated incomplete segregation with the
ADH phenotype. Although the precise mechanism and role of PCSK9 in cholesterol metabolism nor the influence of genetic variation in this gene are currently understood, there is reasonable doubt that mutations in PCSK9 actually result in the $\mathrm{ADH}$ phenotype in the Dutch population (submitted for publication). On the contrary, very recent findings show that nonsense mutations in the PCSK9 gene, leading to loss of PCSK9 function, are associated with significantly reduced LDL-C levels. ${ }^{12}$

\section{Lipid-lowering treatment of ADH patients Treatment goals}

$\mathrm{ADH}$ patients can currently be divided into three distinct groups: carriers of an LDLR mutation (FH), carriers of an APOB mutation (FDB) and non-LDLR/non-APOB patients (FH3). The phenotypic expression, in terms of levels of LDL-C and onset and severity of atherosclerotic disease, varies considerably in each group. Reduction of high cholesterol levels in ADH patients will lead to a reduced CVD risk. The first line of treatment is dietary therapy, but efficacy is usually poor. Cholesterol levels almost always remain high after dietary therapy and the drugs of first choice are 3-hydroxy-3-methylglutaryl-coenzyme A (HMGCoA) reductase inhibitors (statins), which have been proven to reduce cardiovascular events. Since the CVD burden differs from patient to patient, treatment goals with these statins for the individual patient depend on the patient's risk status (Table 2 ). ${ }^{3}$

\section{Conventional lipid-lowering treatment}

The most commonly used dose of statin differs for each statin and depends on the potency of the drug. Never- 
theless, many clinical trials with different dosing regimens and duration have proven that the average dose of each statin results in a significant reduction of total cholesterol (17-31\%), LDL-C (26-46\%) and triglycerides (10-17\%), as well as increase of HDL cholesterol (6-12\%) in all ADH patients. ${ }^{13}$ Despite these significant drug-induced changes in cholesterol levels, large proportions of $\mathrm{ADH}$ patients do not achieve the LDL-C goals, as advised by the North American National Cholesterol Education Programme (NCEP). ${ }^{2}$ The Lipid Treatment Assessment Project (L-TAP), which included 4888 patients from five different regions of the United States, collected between 1996 and 1997, showed that overall only $38 \%$ of $\mathrm{ADH}$ patients on statin treatment achieved NCEP-specified LDL-C target levels. ${ }^{14}$ Target levels are mainly achieved in the low-risk group of patients in which a smaller reduction in LDL-C is usually required to achieve set goals. Within this group, $68 \%$ of patients are successfully treated. In the high-risk group of patients only $37 \%$ achieve their target LDL-C levels, while in the group of patients with established CVD and thus at the highest risk for future CVD only $18 \%$ are successfully treated with statins. ${ }^{14}$ There are several possible reasons to explain the failure to achieve treatment goals in $\mathrm{ADH}$ patients. Mostly, patients who initiate treatment on statin remain at the initial dose and are not having their dosage titrated to achieve a larger LDL-C reduction. ${ }^{15-17}$ Additionally, not all recommended doses of statins reduce LDL-C levels sufficiently.

\section{Aggressive lipid-lowering treatment}

Recent data suggest that aggressive lipid-lowering treatment can be more beneficial in reducing cholesterol levels compared to the usual care treatment. ${ }^{18,19}$ In the 2-year Atorvastatin versus Simvastatin on Atherosclerosis Progression (ASAP) study, patients with severely elevated cholesterol levels were treated with a conventional treatment of $40 \mathrm{mg}$ simvastatin or a more aggressive approach of $80 \mathrm{mg}$ atorvastatin. The group of patients on aggressive therapy showed significant higher reduction in total cholesterol (42 versus 34\%), LDL-C (51 versus 41\%) and triglycerides (29 versus $18 \%$ ), with no significant differences in HDL cholesterol change versus the conventional treated group. ${ }^{18}$ In the 1-year Arterial Biology for the Investigation of the Treatment Effects of Reducing Cholesterol (ARBITER) study, which included patients with moderately high cholesterol levels, similar differences were seen. ${ }^{19}$ Patients treated with $80 \mathrm{mg}$ atorvastatin were compared to patients treated with $40 \mathrm{mg}$ pravastatin. Total cholesterol (36 versus 19\%), LDL-C (49 versus 29\%) and triglycerides (36 versus $8 \%$ ) were significantly more reduced in the $80 \mathrm{mg}$ atorvastatin group compared to the $40 \mathrm{mg}$ pravastatin group. Even more recently, titrated treatment up to $80 \mathrm{mg}$ of rosuvastatin revealed LDL-C reductions up to $59.6 \% .^{20}$

\section{Combined lipid-lowering treatment}

To be able to treat patients to target, it becomes more and more evident that, besides increasing the dose of statin, combination of statins with other classes of lipid-lowering drugs can be beneficial. For patients with high triglyceride levels, statin therapy is often combined with fibrates or nicotinic acid. For $\mathrm{ADH}$ patients receiving the highest statin dose available and not on target, additional cholesterol-lowering efficiency can be achieved by addition of the cholesterol absorption inhibitor, ezetimibe. Several studies have been performed in which coadministration of ezetimibe with statins is well tolerated with a safety profile similar to that of statin monotherapy. ${ }^{21}$ The overall effect of monotherapy with $10 \mathrm{mg}$ ezetimibe on cholesterol levels varies between -8 and $-17 \%$ (average $-13.5 \pm 2.9 \%$ ) for LDL cholesterol, 0 and $+6 \%$ (average $3.2 \pm 1.8 \%$ ) for HDL cholesterol, and -6 and $-15 \%$ (average $-9.3 \pm 2.6 \%$ ) for triglycerides. $^{22-25}$ Since ezetimide does not only have positive influence on LDL-C but also on HDL cholesterol and triglycerides, coadministration of ezetimide with any statin offers a well-tolerated and highly efficacious new treatment regimen to treat $\mathrm{ADH}$ patients to target.

\section{Carotid intima-media thickness in ADH patients Carotid IMT as a surrogate marker}

The atherosclerotic process, which eventually results in CVD, starts with early morphological changes in arterial walls, characterized by subendothelial accumulation of cholesterol in macrophages and smooth muscle cell proliferation, which finally results in arterial wall thickening. ${ }^{26}$ High-resolution B-mode ultrasound measurements of the intima media thickness (IMT) of the carotid artery is considered a surrogate marker for atherosclerosis. ${ }^{27}$ The IMT is measured by B-mode ultrasound imaging, permitting a safe, noninvasive real-time resolution assessment of arterial walls. For measurement of IMT, three segments in the carotid artery are defined: the common carotid artery (CCA), the carotid bulb (CB) and the internal carotid artery (ICA). The near and far walls of the three segments on the right and left carotid arteries are scanned, resulting in the combined assessment of 12 segments to provide an accurate estimation of the overall atherosclerotic changes in the arteries (Figure 1).

The IMT can be measured as a continuous variable from childhood to older age, in patients as well as in healthy controls. $^{28}$ Multiple observation studies have been performed that show that increases in carotid artery IMT are positively associated with increased LDL-C levels, reduced HDL cholesterol levels and increased risk of CVD. ${ }^{29-31}$ In a recent study, the atherosclerotic progression from childhood into seniority was estimated in $\mathrm{ADH}$ patients and in controls. ${ }^{27}$ It was found that IMT increase with age was at least twice as rapid in $\mathrm{ADH}$ subjects compared to controls (0.009 and $0.004 \mathrm{~mm} /$ year, respectively). The 


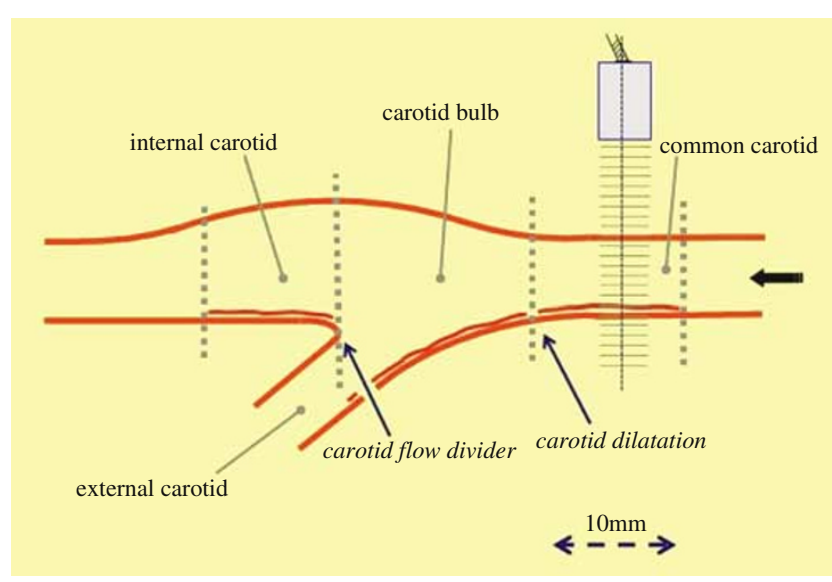

Figure 1 Schematic diagram of the longitudinal view of the carotid artery. The far wall is shown as a double-line pattern, which is a representative of the intima-media complex. The measurements are performed at the far wall of three defined segments: common carotid, carotid bulb and internal carotid.

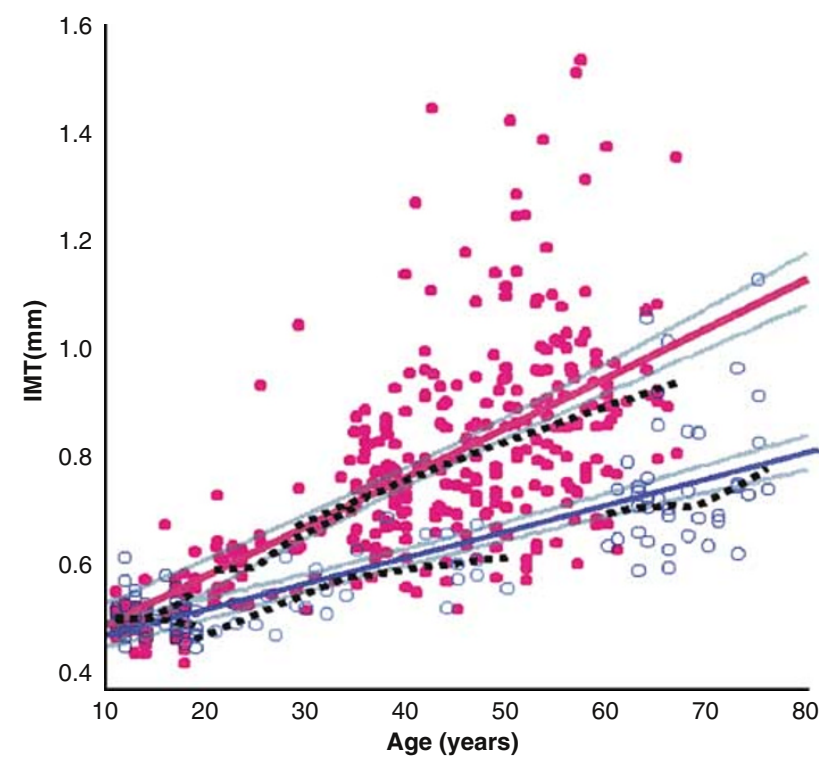

Figure 2 Arterial wall thickness progression in persons with $\mathrm{ADH}$ (LDL cholesterol $7.2+2.0 \mathrm{mmol} / \mathrm{l}$; IMT $0.79+0.20 \mathrm{~mm}$ (range $0.45-$ 1.53); $n=315$; filled dots) and healthy controls (LDL cholesterol $3.4 \pm 0.8 \mathrm{mmol} / \mathrm{l} ; \mathrm{IMT} 0.63 \pm 0.14 \mathrm{~mm}$ (range $0.48-1.14$ ); $n=118$; open dots). IMT increase was calculated by linear regression. On average, healthy controls reach an IMT of approximately $0.8 \mathrm{~mm}$ at age 80 , whereas ADH subjects reach this value, if untreated, around the age of 40 years.

mean differential IMT change between ADH and controls was $0.005 \mathrm{~mm} /$ year $(P<0.001$, Figure 2$)$.

\section{Carotid IMT as a treatment goal}

Several trials with lipid-lowering drugs have shown that carotid IMT progression can be slowed down significantly in subjects receiving conventional statin treatment. ${ }^{32,33}$ Other trials with the same conventional treatment demonstrated not only a reduced progression but even a regression of the IMT. ${ }^{34-36}$ This regression is even more prominent when patients are receiving aggressive treatment. ${ }^{18,19,37}$ Patients with ADH and severely raised LDL-C showed significant regression of IMT when LDL-C was lowered by at least $45 \% .{ }^{38}$ In the ASAP study, patients with severely elevated LDL-C levels were treated with $40 \mathrm{mg}$ simvastatin versus $80 \mathrm{mg}$ atorvastatin. The aggressive treatment group showed a carotid IMT with a mean change of $-0.031 \mathrm{~mm} \quad(95 \% \mathrm{CI}-0.007$ to -0.055$)$, while the conventional treatment group showed an IMT with a mean change of $+0.036 \mathrm{~mm} \mathrm{(95 \%} \mathrm{CI} 0.014-0.058$; $P=0.0001)$ after a 2 -year treatment. ${ }^{18}$

True regression of carotid atherosclerosis was seen in two-thirds of the aggressively treated patients in whom LDL-C was reduced by half. ${ }^{18}$ Similar results were seen in the ARBITER study in which patients with moderate to high elevated LDL-C levels were receiving $80 \mathrm{mg}$ atorvastatin versus $40 \mathrm{mg}$ pravastatin. Atorvastatin induced progressive IMT regression over 12 months (change in IMT: $-0.034 \pm 0.021 \mathrm{~mm})$, whereas IMT was stable in the pravastatin group (change in IMT: $0.025 \pm 0.017 \mathrm{~mm}$; $P=0.03){ }^{19}$

\section{ADH children as model for atherogenesis}

In children with $\mathrm{ADH}$, the disease is mostly asymptomatic. ${ }^{39}$ Nevertheless, even in the general population, autopsy reports of healthy children show atherosclerotic lesions at young age. Since morphological changes of the arterial wall start early in life, it is evident that treatment of patients with a high-risk profile for CVD should start as early as possible. To identify those patients who are at high risk for developing early $\mathrm{CVD}$, screening for $\mathrm{ADH}$ should start in childhood. ${ }^{39}$

In a large cohort study with more than 1000 children of $\mathrm{ADH}$ relatives, the best cutoff value of LDL cholesterol to diagnose $\mathrm{ADH}$ was determined. LDL-C levels below $3.5 \mathrm{mmol} / \mathrm{l}(135 \mathrm{mg} / \mathrm{dl})$ were only found in $4.3 \%$ of children with a mutation in LDLR. LDL-C levels above this level had a 0.98 post-test probability if having a $L D L R$ mutation. Thus, when the diagnosis of $\mathrm{FH}$ is certain in relatives, simple measurement of LDL cholesterol allows an accurate diagnosis of $\mathrm{FH}$ in childhood and treatment of these children should be initiated. ${ }^{40}$ The recommended therapy for $\mathrm{ADH}$ children consists of dietary intervention and life-style changes. However, the long-term efficacy of stringent dietary interventions in children is very poor. The NCEP guidelines for children recommend that pharmacological therapy can be considered in patients whose LDL cholesterol is above $160 \mathrm{mg} / \mathrm{dl}(4.1 \mathrm{mmol} / \mathrm{l})$ when other CVD risk factors are present, or above $190 \mathrm{mg} / \mathrm{dl}$ $(4.9 \mathrm{mmol} / \mathrm{l})$ when no other risk factors are present. ${ }^{41}$ Pharmacological therapy should be instituted when 
cholesterol levels remain persistently above the cutoff points despite dietary and other lifestyle intervention. However, the NCEP guidelines for adults have recently become more stringent, which could provide a stimulus for updating the guidelines for children as well. ${ }^{41}$

Statin therapy was until recently only available for adults, and bile acid sequestrants were considered the drugs of choice in the treatment of children with $\mathrm{ADH}$, but the lipid-lowering efficacy is modest and the long-term compliance is poor. ${ }^{42}$ Therefore, in recent years several trials have been conducted to establish the safety and efficacy of statins in $\mathrm{ADH}$ children. All randomized controlled trials convincingly demonstrated that statins are effective and seem safe in the treatment of hypercholesterolaemic children, even aggressive lipid-lowering strategies. $^{43-47} \mathrm{ADH}$ in children is also accompanied by endothelial dysfunction and increased carotid IMT as compared with their healthy siblings. ${ }^{48-51}$ In fact, those children have a five-fold more rapid increase of carotid arterial wall IMT during childhood years than their unaffected siblings. This more rapid increase leads to detectable IMT deviation from the age of 12 years onwards. Moreover, it was shown that LDL cholesterol, age and gender contribute to the progression of carotid IMT in ADH children. ${ }^{51}$ A large randomized controlled study with ADH children demonstrated that 2-year pravastatin therapy was effective and safe, with regard to growth and sexual maturation. Moreover, it was clearly shown that 2-year pravastatin induced regression of carotid IMT as compared to the placebo-treated children.

An other placebo-controlled trial demonstrated that early initiation of simvastatin therapy restored endothelial dysfunction. ${ }^{52}$ Thus, increased arterial wall thickness and similarly endothelial dysfunction as present in children with $\mathrm{FH}$ are reversible with statin therapy. This underscores the need for early treatment with statins to prevent the children for future CVD.

\section{ADH in the Netherlands Identification of ADH index cases}

Collecting DNA samples of clinically diagnosed $\mathrm{ADH}$ patients was started in the Netherlands in 1991 and, to date, the $\mathrm{ADH}$ cohort of index cases has expanded significantly due to a network of 64 Lipid Clinics located throughout the Netherlands. All clinically diagnosed ADH patients are systematically screened for mutations in the $L D L R$ and $A P O B$ genes. So far, this has resulted in the identification of 278 causative genetic variants in $L D L R$, including point mutations, small deletions and insertions, and large rearrangements in patients from Dutch descent. ${ }^{8}$ Additionally, five different causative point mutations were found in the $A P O B$ gene of the Dutch $\mathrm{ADH}$ population. These two types of mutations were found in a total of 2818 index cases. Mutations in $L D L R$ account for approximately
$67 \%$ of $\mathrm{ADH}$ cases in our country. In another approximately $10 \%$, these high cholesterol levels can be explained by the five mutations found in the $A P O B$ gene. This indicates that also in the Dutch population there is strong evidence that other genes besides the $L D L R$ and $A P O B$ genes must be responsible for elevated LDL-C levels. The identification of a third ADH gene, PCSK9, might have explained a large portion of the remaining non-LDL reporter and non-APOB $\mathrm{ADH}$ patients also, since the estimated frequency of mutations in PCSK9 causing ADH was estimated to be between 6.0 and $12.5 \%$. However, after systematic large-scale screening for mutations in this gene in 300 non- $L D L R$ and non- $A P O B$ Dutch ADH patients, only four potential causative genetic variants were found, representing a much lower frequency of $1.3 \%$. More importantly, the mutations found in the PCSK9 gene of our patients did not show complete cosegregating with the ADH phenotype.

\section{Family investigation by genetic fieldwork}

Since the demonstration of a causative mutation provides the only unequivocal diagnosis, identification of mutations in the $L D L R, A P O B$ or new genes responsible for an $\mathrm{ADH}$ phenotype is of major importance for the identification of relatives of these patients. Since most of these relatives are previously undiagnosed with $\mathrm{ADH}$, demonstration of the causative mutation in families leads to early cholesterol-lowering treatment and should eventually reduce cardiovascular morbidity and mortality in this group of ADH patients. ${ }^{53}$ Therefore, in 1994, the national identification programme for $\mathrm{ADH}$ was established in the Netherlands. ${ }^{53}$ Within this programme, first-degree relatives of index cases are contacted and visited by a specialized nurse for blood sampling. The blood samples of these first-degree relatives are then tested for the mutation causing hypercholesterolaemia in the index case. If carrier status is confirmed, the first-degree relatives of these newly identified patients are contacted. In the period between 1994 and 1998, a 2-year follow-up study of 747 previously undiagnosed relatives of index cases with $\mathrm{ADH}$ was conducted. ${ }^{54}$

At screening, 281 (37.6\%) of the patients were already receiving cholesterol-lowering medication, while 466 $(62.4 \%)$ were not. After 2 years, in both groups, almost $80 \%$ of the patients remained on cholesterol-lowering therapy. Although 38\% of the newly identified carriers were already receiving some form of cholesterol-lowering therapy, more than $50 \%$ of the newly identified patients became properly treated, after the confirmation of their carrier status. After identification by the programme, in patients who were already on treatment, LDL-C levels were reduced by an additional $10.5 \%$.

To date, the national identification programme for $\mathrm{ADH}$ resulted in the identification of 21150 relatives examined, of whom 7079 (33\%) relatives were identified as carriers of 


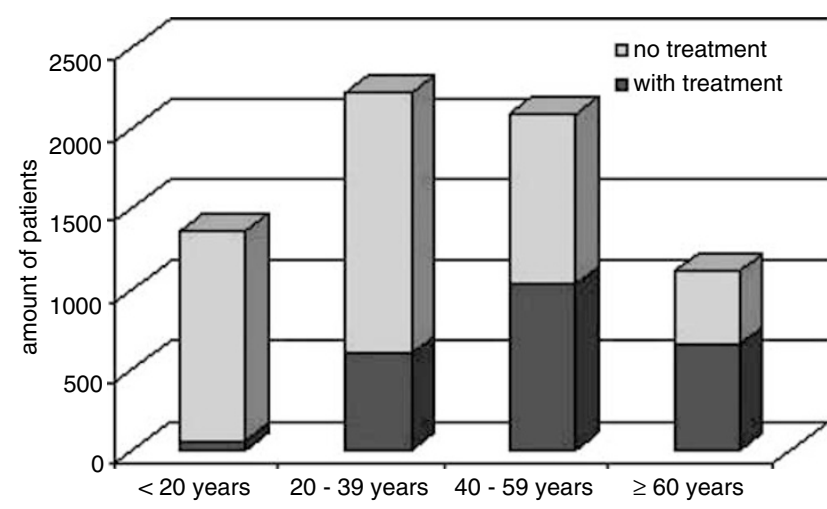

Figure 3 The use of cholesterol-lowering medication in identified $\mathrm{ADH}$ patients divided by age category.

a pathogenic mutation. Of these carriers, 1376 (19\%) were under the age of 20 at the time of examination. Of the 7079 ADH patients identified, only 2463 (34.8\%) patients were on cholesterol-lowering treatment at the time of identification. Cholesterol-lowering treatment is mainly initiated at an age of 60 years and older (60\%), followed by the age category of $40-59$ years (49\%). Of patients in the age category of 20 years and younger, only a minority (5\%) was on cholesterol-lowering treatment (Figure 3).

This indicates that the national programme for $\mathrm{ADH}$ is not only highly efficient in identifying patients at an early age but also provides the opportunity to actually treat these patients early enough in life to reduce morbidity and mortality.

\section{Conclusion}

In contrast to most genetic diseases, efficacious therapy is available for $\mathrm{ADH}$ in the form of life-style changes and lipid-lowering drugs. However, still too few patients are being treated and too few patients are being treated to target. Today, the possibility to treat each individual $\mathrm{ADH}$ patient to target does exist, since the choice of statins is wide, high doses of statins are effective and well-tolerated, and combination treatment is effective in these patients. However, most patients start their treatment at the time they are already at high risk for developing CVD. Therefore, early identification of patients is important. When treatment of these patients is initiated in childhood, the burden of CVD can be reduced significantly.

In summary, (1) $\mathrm{ADH}$ is an excellent model to study atherogenesis in humans; (2) the treatment of ADH should be initiated early, pursued aggressively and should not merely focus on LDL-C; (3) ADH meets all the criteria for active identification in the population at large; (4) $\mathrm{ADH}$ children are an excellent model to study the process of arterial wall thickening in an early asymptotic state. The identification of these children should have high priority in order to reduce morbidity and mortality as a consequence of atherosclerosis, the most common cause of death worldwide.

\section{References}

1 Goldstein JL, Hobbs HH, Brown MS, Scriver CR, Beaudet AL, Sly WS, Valle D (eds): The metabolic and molecular basis of inherited disease. New York: McGraw-Hill, 2001, pp 2863-2913.

2 Summary of the second report of the National Cholesterol Education Program (NCEP) Expert Panel on Detection, Evaluation, and Treatment of High Blood Cholesterol in Adults (Adult Treatment Panel II). JAMA 1993; 269: 3015-3023.

3 Grundy SM, Cleeman JI, Merz CN et al: Implications of recent clinical trials for the National Cholesterol Education Program Adult Treatment Panel III Guidelines. J Am Coll Cardiol 2004; 44: $720-732$.

4 Scientific Steering Committee on behalf of the Simon Broome Register Group: Mortality in treated heterozygous familial hypercholesterolaemia: implications for clinical management. Atherosclerosis 1999; 142: 105-112.

5 LDL-Receptor Gene in FH - Mutation Database http://www.ucl. ac.uk/fh.

6 UMD-LDL-receptor Database http://www.umd.necker.fr.

7 Defesche JC, Pricker KL, Hayden MR et al: Familial defective apolipoprotein B-100 is clinically indistinguishable from familial hypercholesterolemia. Arch Intern Med 1993; 153: 2349-2356.

8 Fouchier SW, Defesche JC, Umans-Eckenhausen MAW et al: The molecular basis of familial hypercholesterolemia in The Netherlands. Hum Genet 2001; 109: 602-615.

9 Abifadel M, Varret M, Rabes JP et al: Mutations in PCSK9 cause autosomal dominant hypercholesterolemia. Nat Genet 2003; 34: $154-156$.

10 Leren TP: Mutations in the PCSK9 gene in Norwegian subjects with autosomal dominant hypercholesterolemia. Clin Genet 2004; 65: 419-422.

11 Timms KM, Wagner S, Samuels ME et al: A mutation in PCSK9 causing autosomal-dominant hypercholesterolemia in a Utah pedigree. Hum Genet 2004; 114: 349-353.

12 Cohen J, Pertsemlidis A, Kotowski IK, Graham R, Garcia CK, Hobbs HH: Low LDL-cholesterol in individuals of African descent resulting from frequent nonsense mutations in PCSK9. Nat Genet, published online 16 January 2005; doi 10.1038/ng1509.

13 Edwards JE, Moore RA: Statins in hypercholesterolaemia: a dosespecific meta-analysis of lipid changes in randomised, double blind trials. BMC Fam Pract 2003; 4: 18.

14 Pearson TA, Laurora I, Chu $\mathrm{H}$ et al: The lipid treatment assessment project (L-TAP): a multicenter survey to evaluate the percentages of dyslipidemic patients receiving lipid-lowering therapy and achieving low-density lipoprotein cholesterol goals. Arch Intern Med 2000; 160: 459-467.

15 Marcelino JJ, Feingold KR: Inadequate treatment with HMG-CoA reductase inhibitors by health care providers. Am J Med 1996; 100: $605-610$.

16 Schectman G, Hiatt J: Drug therapy for hypercholesterolemia in patients with cardiovascular disease: factors limiting achievement of lipid goals. Am J Med 1996; 100: 197-204.

17 Schrott HG, Bittner V, Vittinghoff E et al: Adherence to National Cholesterol Education Program Treatment goals in postmenopausal women with heart disease. The Heart and Estrogen/ Progestin Replacement Study (HERS). The HERS Research Group. JAMA 1997; 277: 1281-1286.

18 Smilde TJ, Van Wissen S, Wollersheim $\mathrm{H}$ et al: Effect of aggressive versus conventional lipid lowering on atherosclerosis progression in familial hypercholesterolaemia (ASAP): a prospective, randomised, double-blind trial. Lancet 2001; 357: 577-581. 
19 Taylor AJ, Kent SM, Flaherty PJ et al: ARBITER: Arterial Biology for the Investigation of the Treatment Effects of Reducing Cholesterol: a randomized trial comparing the effects of atorvastatin and pravastatin on carotid intima medial thickness. Circulation 2002; 106: $2055-2060$.

20 Schwartz GG, Bolognese MA, Tremblay BP et al: Efficacy and safety of rosuvastatin and atorvastatin in patients with hypercholesterolemia and a high risk of coronary heart disease: a randomized, controlled trial. Am Heart J 2004; 148: e4.

21 Gagne C, Bays HE, Weiss SR et al: Efficacy and safety of ezetimibe added to ongoing statin therapy for treatment of patients with primary hypercholesterolemia. Am J Cardiol 2002; 90: 1084-1091.

22 Kerzner B, Corbelli J, Sharp S et al: Efficacy and safety of ezetimibe coadministered with lovastatin in primary hypercholesterolemia. Am J Cardiol 2003; 91: 418-424.

23 Davidson MH, McGarry T, Bettis R et al: Ezetimibe coadministered with simvastatin in patients with primary hypercholesterolemia. J Am Coll Cardiol 2002; 40: 2125-2134.

24 Feldman $\mathrm{T}$, Koren $\mathrm{M}$, Insull Jr $\mathrm{W}$ et al: Treatment of high-risk patients with ezetimibe plus simvastatin co-administration versus simvastatin alone to attain National Cholesterol Education Program Adult Treatment Panel III low-density lipoprotein cholesterol goals. Am J Cardiol 2004; 93: 1481-1486.

25 Ballantyne CM, Houri J, Notarbartolo A et al: Effect of ezetimibe coadministered with atorvastatin in 628 patients with primary hypercholesterolemia: a prospective, randomized, double-blind trial. Circulation 2003; 107: 2409-2415.

26 Lusis AJ: Atherosclerosis. Nature 2000; 407: 233-241.

27 De Groot E, Hovingh GK, Wiegman A et al: Measurement of arterial wall thickness as a surrogate marker for atherosclerosis. Circulation 2004; 109: III33-III38.

28 Blankenhorn DH, Hodis HN: George Lyman Duff Memorial Lecture. Arterial imaging and atherosclerosis reversal. Arterioscler Thromb 1994; 14: 177-192.

29 Bots ML, Hoes AW, Koudstaal PJ et al: Common carotid intimamedia thickness and risk of stroke and myocardial infarction: the Rotterdam Study. Circulation 1997; 96: 1432-1437.

30 Heiss G, Sharrett AR, Barnes R et al: Carotid atherosclerosis measured by B-mode ultrasound in populations: associations with cardiovascular risk factors in the ARIC study. Am J Epidemiol 1991; 134: 250-256.

31 Van Dam MJ, de Groot E, Clee SM et al: Association between increased arterial-wall thickness and impairment in ABCA1-driven cholesterol efflux: an observational study. Lancet 2002; 359: 37-42.

32 Crouse III JR, Byington RP, Bond MG et al: Pravastatin, lipids, and atherosclerosis in the carotid arteries (PLAC-II). Am J Cardiol 1995; 75: 455-459.

33 Salonen R, Nyyssonen K, Porkkala E et al: Kuopio Atherosclerosis Prevention Study (KAPS). A population-based primary preventive trial of the effect of LDL lowering on atherosclerotic progression in carotid and femoral arteries. Circulation 1995; 92: 1758-1764.

34 MacMahon S, Sharpe N, Gamble G et al: Effects of lowering average of below-average cholesterol levels on the progression of carotid atherosclerosis: results of the LIPID Atherosclerosis Substudy. LIPID Trial Research Group. Circulation 1998; 97: $1784-1790$.

35 Jukema JW, Bruschke AV, van Boven AJ et al: Effects of lipid lowering by pravastatin on progression and regression of coronary artery disease in symptomatic men with normal to moderately elevated serum cholesterol levels. The Regression Growth Evaluation Statin Study (REGRESS). Circulation 1995; 91: $2528-2540$.

36 Furberg CD, Adams Jr HP, Applegate WB et al: Effect of lovastatin on early carotid atherosclerosis and cardiovascular events.
Asymptomatic Carotid Artery Progression Study (ACAPS) Research Group. Circulation 1994; 90: 1679-1687.

37 Blankenhorn DH, Azen SP, Kramsch DM et al: Coronary angiographic changes with lovastatin therapy. The Monitored Atherosclerosis Regression Study (MARS). The MARS Research Group. Ann Intern Med 1993; 119: 969-976.

38 Smilde TJ, Van den Berkmortel FW, Wollersheim $\mathrm{H}$ et al: The effect of cholesterol lowering on carotid and femoral artery wall stiffness and thickness in patients with familial hypercholesterolaemia. Eur J Clin Invest 2000; 30: 473-480.

39 Rodenburg J, Vissers MN, Wiegman A, Trip MD, Bakker HD, Kastelein JJ: Familial hypercholesterolemia in children. Curr Opin Lipidol 2004; 15: 405-411.

40 Wiegman A, Rodenburg J, de Jongh S et al: Family history and cardiovascular risk in familial hypercholesterolemia: data in more than 1000 children. Circulation 2003; 107: 1473-1478.

41 American Academy of Pediatrics Committee on Nutrition: Statement on cholesterol: Pediatrics 1992; 90: 469-473.

42 Tonstad S, Knudtzon J, Sivertsen M et al: Efficacy and safety of cholestyramine therapy in peripubertal and prepubertal children with familial hypercholesterolemia. J Pediatr 1996; 129: 42-49.

43 Stein EA, Illingworth DR, Kwiterovich Jr PO et al: Efficacy and safety of lovastatin in adolescent males with heterozygous familial hypercholesterolemia: a randomized controlled trial. JAMA 1999; 281: 137-144.

44 Knipscheer HC, Boelen CC, Kastelein JJ et al: Short-term efficacy and safety of pravastatin in 72 children with familial hypercholesterolemia. Pediatr Res 1996; 39: 867-871.

45 McCrindle BW, Ose L, Marais AD: Efficacy and safety of atorvastatin in children and adolescents with familial hypercholesterolemia or severe hyperlipidemia: a multicenter, randomized, placebo-controlled trial. J Pediatr 2003; 143: 74-80.

46 De Jongh S, Ose L, Szamosi T et al: Efficacy and safety of statin therapy in children with familial hypercholesterolemia: a randomized, double-blind, placebo-controlled trial with simvastatin. Circulation 2002; 106: 2231-2237.

47 Wiegman A, Hutten BA, de Groot E et al: Efficacy and safety of statin therapy in children with familial hypercholesterolemia: a randomized controlled trial. JAMA 2004; 292: 331-337.

48 De Jongh S, Lilien MR, Bakker HD et al: Family history of cardiovascular events and endothelial dysfunction in children with familial hypercholesterolemia. Atherosclerosis 2002; 163: 193-197.

49 Tonstad S, Joakimsen O, Stensland-Bugge E et al: Risk factors related to carotid intima-media thickness and plaque in children with familial hypercholesterolemia and control subjects. Arterioscler Thromb Vasc Biol 1996; 16: 984-991.

50 Slyper AH: What vascular ultrasound testing has revealed about pediatric atherogenesis, and a potential clinical role for ultrasound in pediatric risk assessment. J Clin Endocrinol 2004; 89: 3089-3095.

51 Wiegman A, de Groot E, Hutten BA et al: Arterial intima-media thickness in children heterozygous for familial hypercholesterolaemia. Lancet 2004; 363: 369-370.

52 De Jongh S, Lilien MR, Op 't Rood J et al: Early statin therapy restores endothelial function in children with familial hypercholesterolemia. J Am Coll Cardiol 2002; 40: 2117-2121.

53 Umans-Eckenhausen MA, Defesche JC, Sijbrands EJ et al: Review of first 5 years of screening for familial hypercholesterolaemia in the Netherlands. Lancet 2001; 357: 165-168.

54 Umans-Eckenhausen MA, Defesche JC, van Dam MJ et al: Longterm compliance with lipid-lowering medication after genetic screening for familial hypercholesterolemia. Arch Intern Med 2003; 163: $65-68$. 